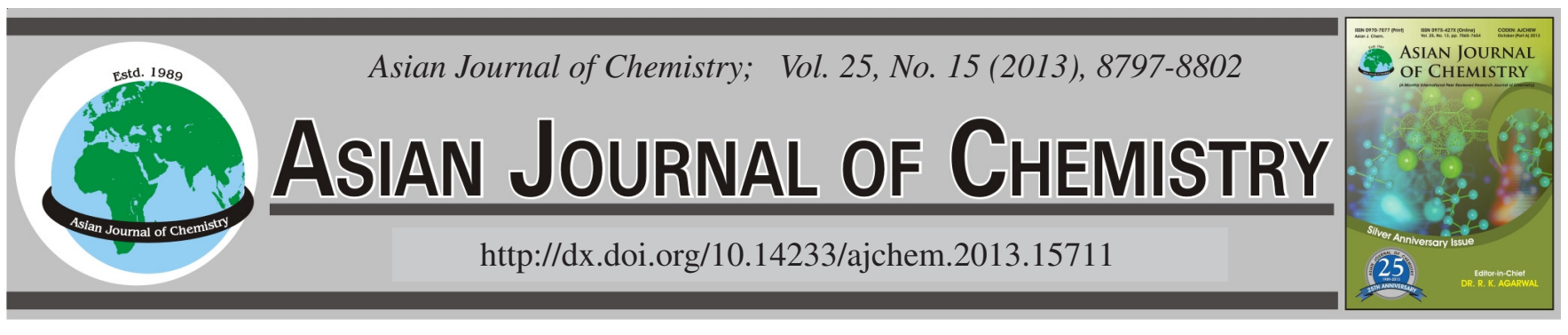

\title{
TG-FTIR Study of Degradation Mechanism and Pyrolysis Products of High Molecular Polyacrylonitrile with Different Oxidation Degree
}

\author{
Li Zhang ${ }^{1,2}$, ZhILING LiU $^{3}$, YongQIANG Dai ${ }^{1}$ and RiguANG JiN ${ }^{1, *}$
}

\begin{abstract}
${ }^{1}$ State Key Laboratory of Chemical Resource Engineering, Beijing University of Chemical Technology, Beijing 100029, P.R. China ${ }^{2}$ Northwest Research Institute of Chemical Industry, Xi'an 710600, P.R. China
\end{abstract}

${ }^{3}$ Research Institute of YangChang Petroleum (Group) Co., Ltd., Xi'an 710075, P.R. China

*Corresponding author: E-mail: leeger_zl@163.com

(Received: 1 May 2013;

Accepted: 29 August 2013)

AJC-14052

\begin{abstract}
Thermal degradation of both high molecular polyacrylonitrile precursor fiber and pre-oxidation fibers with different extent of stabilization were studied in $\mathrm{N}_{2}$ atmospheres using thermogravimetric analysis coupled with Fourier transform Infrared analysis (TG-FTIR). Degradation mechanism and volatile products at various temperatures of each sample were studied. The results show that the fibers with higher stabilization were more stable. It is indicated that degradation process of fibers can be divided into three stages and most of the weight loss occurs at the second stage. The gaseous products such as $\mathrm{H}_{2} \mathrm{O}, \mathrm{NH}_{3}, \mathrm{HCN}, \mathrm{CO}$ and $\mathrm{CO}_{2}$ are formed, meanwhile, the amount of volatile products of fibers were closely related to stabilization of fibers.
\end{abstract}

Key Words: Polyacrylonitrile, Degradation, TG-FTIR, Extent of stabilization.

\section{INTRODUCTION}

The demand of carbon fiber which has been increasing exponentially in the past decades suggests that the material may be one of the most successful commercialized products ${ }^{1,2}$. Its excellent properties, including low density, high stiffness and strength, good resistance to chemical and environmental effects have earned carbon fibers an important place in both civilian usages and high-tech areas such as aerospace, civil engineering, military and motors ports, along with other competition sports ${ }^{1,3-5}$. There are many precursors, such as polyacrylonitrile, rayon, pitch, lignin, polyethylene and poly ( $p$ phenylene benzobisoxazole) to produce carbon fiber. Among these precursors, polyacrylonitrile is one of the most widely used precursor polymers for making high performance carbon fibers ${ }^{6-10}$. However, the production of polyacrylonitrile-based carbon fiber is very complicated process and parameters of each process have a strong influence on the reluctant carbon fiber, particularly for thermal stabilization ${ }^{11}$.

Thermal stabilization of polyacrylonitrile precursor, which is commonly performed in air between $180-30{ }^{\circ} \mathrm{C}$, is an essential and most time-consuming step in the producing carbon fibers $^{12}$. It has been known that during the stabilization polyacrylonitrile fibers undergo various chemical and physical changes due to a variety of exothermic chemical reactions, including dehydrogenation, cyclization, oxidation, crosslinking and fragmentation ${ }^{13-15}$. During the process, the linear polyacry- lonitrile polymer chains are converted into a infusible ladder polymer containing aromatized and aliphatic groups which significantly enhanced thermal stability, easily facilitating heating to high temperature for carbonization ${ }^{16,17}$. Previous researchers have studied the ladder polyacrylonitrile structure, in the beginning, Houtz etc. ${ }^{18-22}$ had proposed the pyridine structures [Fig. 1(a)], considering the precursor was stabilized in air atmosphere, the cyclized structure may be oxidized, then. Standage and others ${ }^{23-25}$ proposed including those containing bridging ether links, those containing carbonyl group and those in which each nitrogen atom donates its lone pair of electron to an oxygen [Fig. 1(b-d)] accounting for the presence of oxygen, finally, Morita et al. ${ }^{26}$ proposed a model [Fig. 1(e)] which is well accepted, containing acridone (40\%), pyridine ring (30\%), oxidized naphthyridine ring $(20 \%)$ and other structures $(10 \%)$ considering all the possible reactions during stabilization.

Aromatic structure determines heat-resistance of stabilized fibers. Increasing heat treated temperature and extent the stabilization time can increase the extent of stabilization and enhance the infusibility of fiber. However, the precursor containing non-carbon atoms or introduced in stabilization will expelled in carbinzation, leaving microporous on the surface of the fibers and the properties of the reluctant carbon fiber decreased significantly. So the pyrolysis of detailed study of the stabilized fiber with different aromatization degree in $\mathrm{N}_{2}$ atmosphere is essential. 


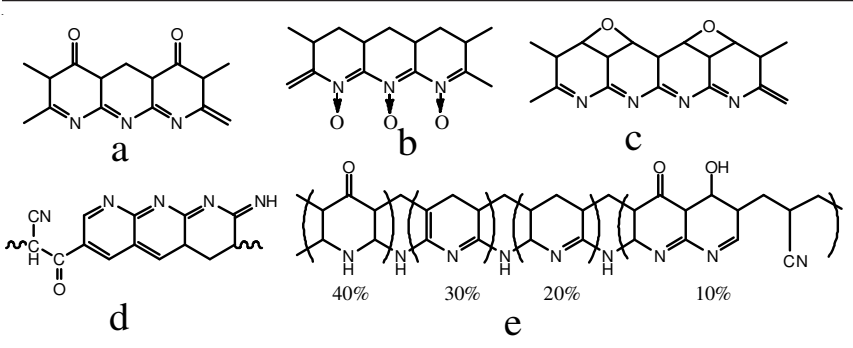

Fig. 1. Proposed structures of oxidized polyacrylonitrile: (a) bridging ether links; (b) carbonyl groups; (c) donation of lone pair electron to oxygen atom; (d) carbonyl groups; (e) model

In the present study, the thermal degradation behaviour of stabilized polyacrylonitrile fiber with different aromatization degree ( stabilized at $25^{\circ} \mathrm{C}$ for 0,30 and $60 \mathrm{~min}$, respectively) was studied by TG-FTIR to analyze the changes of the evolved gases at different temperature. Characteristics and mechanism of thermal degradation are described.

\section{EXPERIMENTAL}

High molecular polyacrylonitrile fibers were conducted at $25^{\circ} \mathrm{C}$ and in a precision controlled tube furnace with temperature accuracy of $1{ }^{\circ} \mathrm{C}$. After the temperature in furnace reached to the settled temperature, precursor fibers were placed into the furnace. Pre-oxidation reactions started immediately and samples with different reaction degree were obtained at various reaction time $(0,30,60 \mathrm{~min})$.

FTIR spectroscopy: Fourier transform infrared (FTIR) measurement was conducted on an American Bruker Vector 22 spectrometer using $\mathrm{KBr}$ disks pressed by mixing $1 \mathrm{mg}$ sample which was dried at $80^{\circ} \mathrm{C}$ under vacuum for $24 \mathrm{~h}$, with $200 \mathrm{mg} \mathrm{KBr}$. The FTIR spectra were recorded within the 4000$400 \mathrm{~cm}^{-1}$.

TG-FTIR: TG-FTIR measurements were carried out using a Seiko TG220 thermogravimetric analyzer (TG) coupled with a Jasco FTIR7000 Fourier-transform infrared (FTIR) spectrometer equipped with an IR gas cell where the volatiles are analyzed by FTIR spectroscopy. The transfer line consisted of a Teflon tube of $750 \mathrm{~mm}$ in length and heated at a constant temperature of $230{ }^{\circ} \mathrm{C}$. Quantitative analysis of the evolved gases along with the weight loss measurement of the TG balance establishes mass balance. In this study, $8 \mathrm{mg}$ of sample was heated in $\mathrm{N}_{2}$ at the heat rate of $5^{\circ} \mathrm{C} / \mathrm{min}$ from $35-800{ }^{\circ} \mathrm{C}$ for pyrolysis.

\section{RESULTS AND DISCUSSION}

FTIR analysis of fibers with different extent of stabilization: Fig. 2 shows changes of the IR spectra for high molecular polyacrylonitrile fibers heated at $250^{\circ} \mathrm{C}$, for different time. (a) presents the original spectrum of polyacrylonitrile precursor, The band at $2243 \mathrm{~cm}^{-1}$ corresponds to $\mathrm{CN}$ stretching vibration of acrylonitrile unit in the polymer chain, absorption bands at 2939 and $1454 \mathrm{~cm}^{-1}$ were assigned to $\mathrm{CH}_{2}$ stretching and $\mathrm{CH}$ bending vibration, respectively. The assignments of some other absorption bands are given as follows: $1369 \mathrm{~cm}^{-1}$ (bending of the aliphatic $\mathrm{CH}$ group), $1227 \mathrm{~cm}^{-1}$ (twist vibration of $\left.-\mathrm{CH}_{2}\right)^{27}$. The weak absorption at $1632 \mathrm{~cm}^{-1}$ is probably due to termination by disproportionation, which can be confirmed by the discoloration of dilute bromine water ${ }^{28}$, the wide absorption between $3520-3200 \mathrm{~cm}^{-1}$ is correspond to vibration of -OH of unsaturated water. By comparing the spectra of heat treated polyacrylonitrile for different time (0, 30 and $60 \mathrm{~min})$. It is seen that with the extension of heat-treated time, obvious decrease happens to - $\mathrm{CN}$ stretching band $\left(2243 \mathrm{~cm}^{-1}\right)$, which is almost disappeared for long-treated time, so does the $-\mathrm{CH}_{2}$ stretching and -CH bending at 2939 and $1454 \mathrm{~cm}^{-1}$, respectively. The absorption band appearing at $1590 \mathrm{~cm}^{-1}$ was characteristic of $\mathrm{C}=\mathrm{C}$ and $\mathrm{C}=\mathrm{N}$ combinations vibration of ladder structure. As shown in Fig. 2(c), a wide shoulder band appears at $1730 \mathrm{~cm}^{-1}$ due to $\mathrm{C}=\mathrm{O}$ is assigned to stretching of ketone, due to oxygen up taken reaction. The changes of spectra from (a) to (c) indicated that nitrile groups are converted into cyclized $\mathrm{C}=\mathrm{N}$ groups and cyclization, dehydrogenation, even oxidation started progressing to great extent as pre-oxidation proceeded.

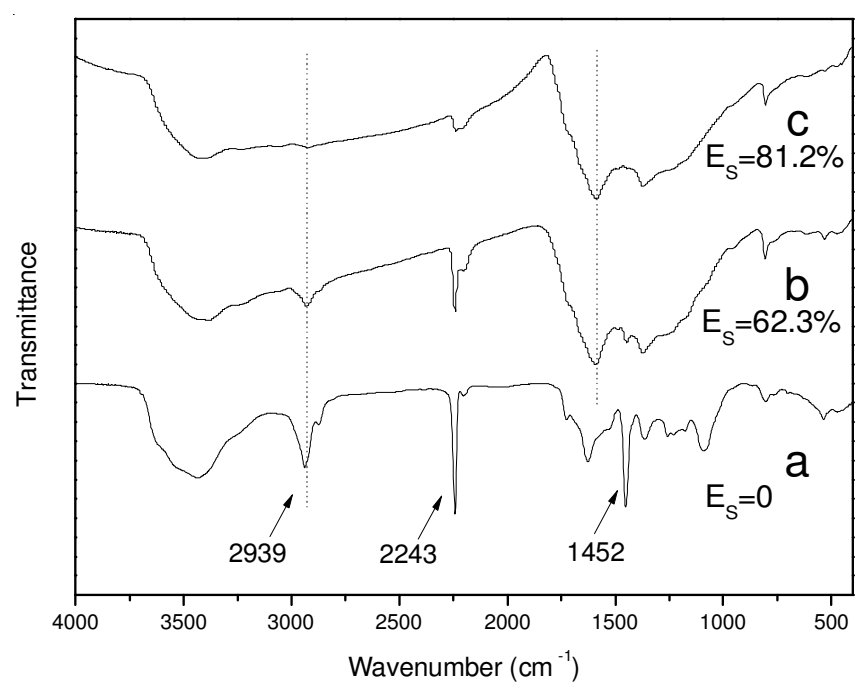

Fig. 2. FTIR spectra of polyacrylonitrile fiber heated for (a) 0 , (b) 30, (c) $60 \mathrm{~min}$ at $250{ }^{\circ} \mathrm{C}$

The extent of stabilization of fibers heated at $250{ }^{\circ} \mathrm{C}$ for different times can be calculated from the following equation:

$$
E s=\frac{A_{1590 \mathrm{~cm}^{-1}}}{A_{2240 \mathrm{~cm}^{-1}}+A_{1590 \mathrm{~cm}^{-1}}}
$$

where $\mathrm{A}$ is the absorbance defined as $\mathrm{A}=\log \left(\mathrm{T}_{0} / \mathrm{T}\right), \mathrm{T}_{0}$ and $\mathrm{T}$ are the transmittances at baseline and maximum, respectively ${ }^{29}$. From calculation the extension of stabilization of the fibers at $250{ }^{\circ} \mathrm{C}$ for $0,30,60 \mathrm{~min}$ is $0,3.1,5.8,(0,62.3$ and $81.2 \%)$, respectively.

TG analysis of the polyacrylonitrile fibers with different extension of stabilizion: TG and DTG curves of pyrolysis of polyacrylonitrile precursor and fibers with different extension of stabilization are shown in and special temperature and weight loss of fibers of pyrolysis are presented in Fig. 3.

Shape of the three TG curves looks familiar and the process of the pyrolysis in $\mathrm{N}_{2}$ atmosphere can be mainly divided into three stages. In the first stage, the weight loss under such temperature range of each fiber is slight for almost none chain secession reaction happens and the weight loss of the fibers were less than $1 \%$. As pyrolysis temperature increasing, the linear polymer chains cannot withstand such high temperature 


\begin{tabular}{|c|c|c|c|c|c|c|c|c|c|}
\hline \multicolumn{10}{|c|}{$\begin{array}{l}\text { TABLE-1 } \\
\text { SPECIAL TEMPERATURES AND WEIGHT LOSSES IN THE PYROLYSIS PROCESS }\end{array}$} \\
\hline & \multicolumn{3}{|c|}{ Stage 1} & \multicolumn{3}{|c|}{$\begin{array}{c}\text { Stage } 2 \\
\end{array}$} & \multicolumn{3}{|c|}{ Stage 3} \\
\hline & $\mathrm{a}$ & $\mathrm{b}$ & $\mathrm{c}$ & $\mathrm{a}$ & $\mathrm{b}$ & $\mathrm{c}$ & $\mathrm{a}$ & $\mathrm{b}$ & $\mathrm{c}$ \\
\hline Temperature range $\left({ }^{\circ} \mathrm{C}\right)$ & $0-266$ & $0-280$ & $0-284$ & $266-445$ & $280-508$ & $284-440$ & $>445$ & $>508$ & $>440$ \\
\hline Residue (\%) & 99.1 & 97.91 & 97.21 & 53.82 & 68.09 & 77.59 & 43.28 & 59.69 & 62.67 \\
\hline Weight loss $(\%)$ & 0.9 & 2.09 & 2.79 & 46.18 & 31.91 & 22.41 & 54.72 & 40.31 & 37.33 \\
\hline
\end{tabular}

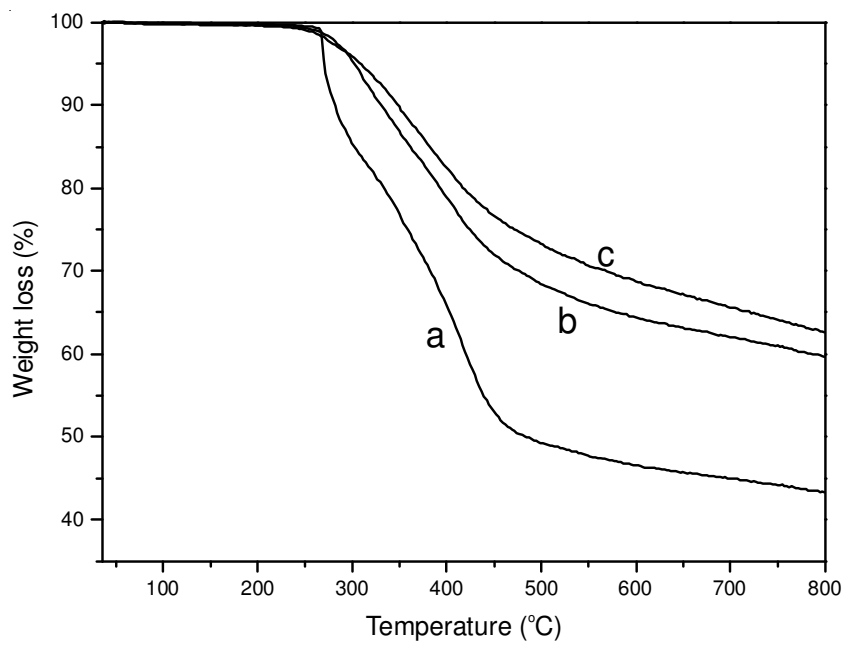

Fig. 3. TG curves of fibers with different extent of stabilization to $800{ }^{\circ} \mathrm{C}$

may crack into volatile gases, resulting into weight loss in second stage of samples dramatically decreased and the on set temperature of fiber were 266,280 and $284{ }^{\circ} \mathrm{C}$ for the fibers of stabilized for $0,30,60 \mathrm{~min}$, respectively and the precursor fibers started its decomposition a bit earlier than the others. Weight loss of precursor fibers decreased from 99.10 to $53.82 \%$ in the second stage from 266 to $445^{\circ} \mathrm{C}$, which is far more loss than the stabilized fiber 29.82 and $23.64 \%$ with different extent of stabilization, since the ladder structure of stabilized fibers can afford the high temperature treatment than the precursor fiber.

As temperature continue increasing, cyclization reactions happens to some of the precursor fibers chains or the residual nitrile groups of stabilized fibers, so that weight loss of the fibers in the third stage decreased, comparing to the former stages and the final weight loss of the fibers to $800{ }^{\circ} \mathrm{C}$ are $52.72,40.31$ and $37.33 \%$. It is noted that the thermal stability of fibers is closely related to the extent of stabilization (Table-1).

3D FTIR spectra analysis: In the present work, TG-FTIR was used to study the volatile gases product during pyrolysis to $800^{\circ} \mathrm{C}$, the $3 \mathrm{D}$ FTIR spectrogram (absorbance wavenumberminute) of volatiles under the heating rate of $5^{\circ} \mathrm{C} / \mathrm{min}$ are shown in Fig. 4. The three-dimensional diagram in which the transmittance corresponding to the vibration modes of the different bonds or functional groups is represented by the wavenumber and the temperature, can provide a qualitative picture of the overall information for the evolution of the gaseous volatiles in the process of the pyrolysis in $\mathrm{N}_{2}{ }^{30}$ (Fig. 4).

Specific FTIR spectra: It is desirable to analyze the IR spectra at different temperatures in each stage of fibers during pyrolysis in order to acquiring the evolution of gases with temperature. Table-2 listed the characteristic absorption bands of gases detected by FTIR spectroscopy. The typical spectra of
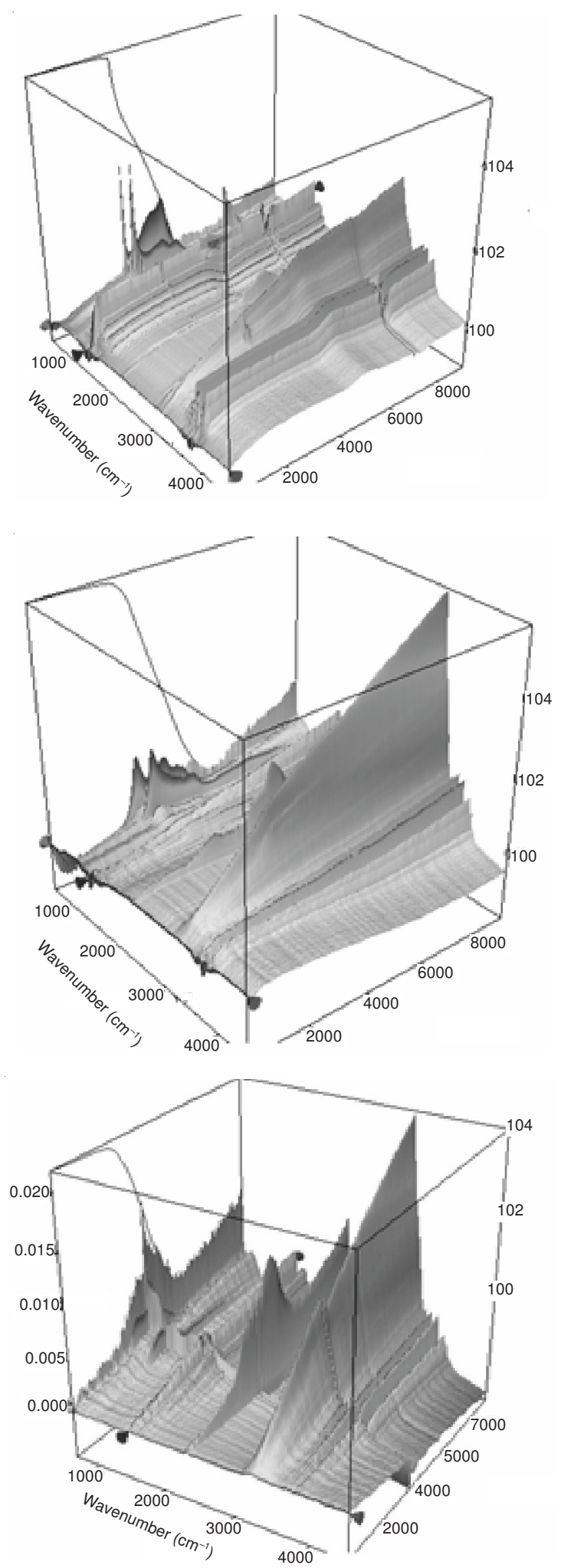

Fig. 4. 3D spectra of TG-FTIR of fibers with different extent of stabilization under the heating rate of $5 \mathrm{k} / \mathrm{min}$ to $800{ }^{\circ} \mathrm{C}$ 


\begin{tabular}{ccccc}
\hline \multicolumn{5}{c}{ TABLE-2 } \\
PEAKS OF THE EVOLUTION OF GASEOUS \\
PRODUCTS DETECTED BY TG-FTIR \\
\hline $\begin{array}{c}\text { Wavnumber } \\
\left(\mathrm{cm}^{-1}\right)\end{array}$ & $\begin{array}{c}\text { Peak } \\
\left(\mathrm{cm}^{-1}\right)\end{array}$ & $\begin{array}{c}\text { Assignment } \\
\text { (bond) }\end{array}$ & Vibration & Product \\
\hline $4000-3500$ & 3737 & $\mathrm{O}-\mathrm{H}$ & Stretching & $\mathrm{H}_{2} \mathrm{O}$ \\
$1873-1275$ & 1507 & $\mathrm{H}-\mathrm{O}-\mathrm{H}$ & Bending & - \\
$2396-2269$ & 2350 & $\mathrm{C}=\mathrm{O}$ & Bending & $\mathrm{CO}_{2}$ \\
$736-605$ & 669 & $\mathrm{C}=\mathrm{O}$ & Stretching & - \\
712 & 3316 & $\mathrm{C} \equiv \mathrm{N}$ & Stretching & $\mathrm{HCN}^{-}$ \\
$3200-2700$ & 2930 & $\mathrm{C}-\mathrm{H}$ & Stretching & $\mathrm{CH}_{4}$ \\
$964-931$ & 962 & $\mathrm{~N}-\mathrm{H}$ & Stretching & $\mathrm{NH}_{4}$ \\
\hline \multicolumn{5}{c}{} \\
\end{tabular}

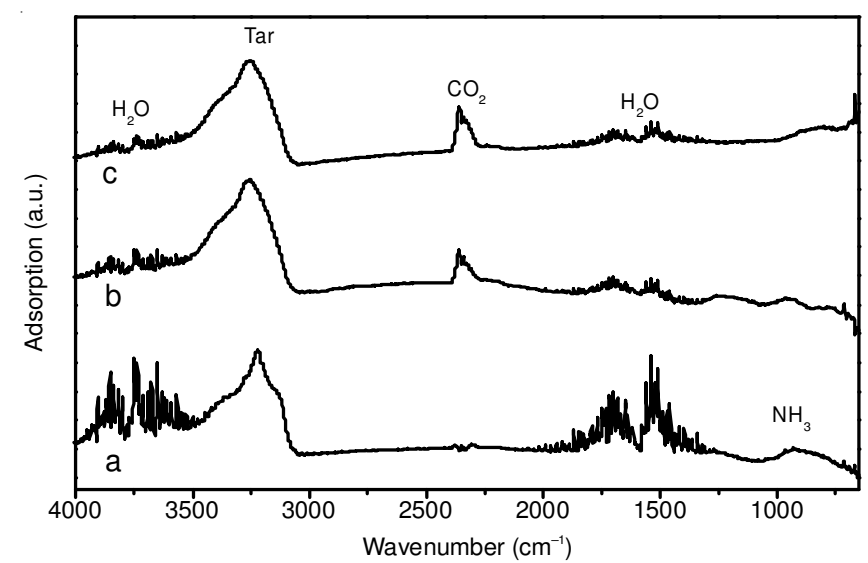

Fig. 5. FTIR spectra for gaseous products at $245^{\circ} \mathrm{C}$ evolving from fibers stabilized for (a) 0; (b) 30; (c) $60 \mathrm{~min}$

volatile gases from polyacrylonitrile precursor stabilized at $250{ }^{\circ} \mathrm{C}$ for 0, 30, 60 min are given in Figs. 5-7, respectively.

Fig. 5 presents a set spectra of fibers with different extent of stabilization at $245^{\circ} \mathrm{C}$, as we can see, the strong intensity at bands around 1500 and $3700 \mathrm{~cm}^{-1}$, also weak the intensity at band of $950 \mathrm{~cm}^{-1}$ which were attributed to $\mathrm{H}_{2} \mathrm{O}$ and $\mathrm{NH}_{3}$, respectively (Fig. 5a), indicating cyclization initiated by itaconic acid, which was dominant in the first stage of pyrolysis for precursor fiber, coupled with small amount of terminal cleavage reaction shown in Fig. 5c). However, the production of $\mathrm{H}_{2} \mathrm{O}\left(1875-1275 \mathrm{~cm}^{-1}\right)$ decreased in (b-c), meanwhile, bands of 2400-2250 and 780-600 $\mathrm{cm}^{-1}$ which were attributed to $\mathrm{CO}_{2}$ could be observed for the crack reaction of oxidized structure shown in (b) it is hard to ascertain the main peak position at the bands around $3336-3287 \mathrm{~cm}^{-1}$, because the interaction between different components may cause interference, hydrocarbon organics (bands around 3336-3287 $\mathrm{cm}^{-1}$ ) could be found dominant in the volatile gases from all kinds of fibers since, more aliphatic chains were been produced to light hydrocarbons $^{31}$. The results suggest that an initial slight weight loss occurs for the release of water from the fibers, besides there was also some decomposition of unstable chains which released $\mathrm{CO}_{2}$ for stabilized fibers.

Fig. 6 shows the FTIR of $352^{\circ} \mathrm{C}$ in second stages in which significant weight loss of the fibers occurred. The presence of intense band at $712 \mathrm{~cm}^{-1}$ in Fig 6(a) reflects the existence of $\mathrm{HCN}$, which was the product of the cyclization of the neighboring nitrile groups shown in (a-b) at low temperature and cross-linking reaction of ladder structure at high temperature shown in (c), meanwhile there were weak intensity at $712 \mathrm{~cm}^{-1}$ can be noticed from Fig. $6(\mathrm{~b}-\mathrm{c})$ for the cyclization of the

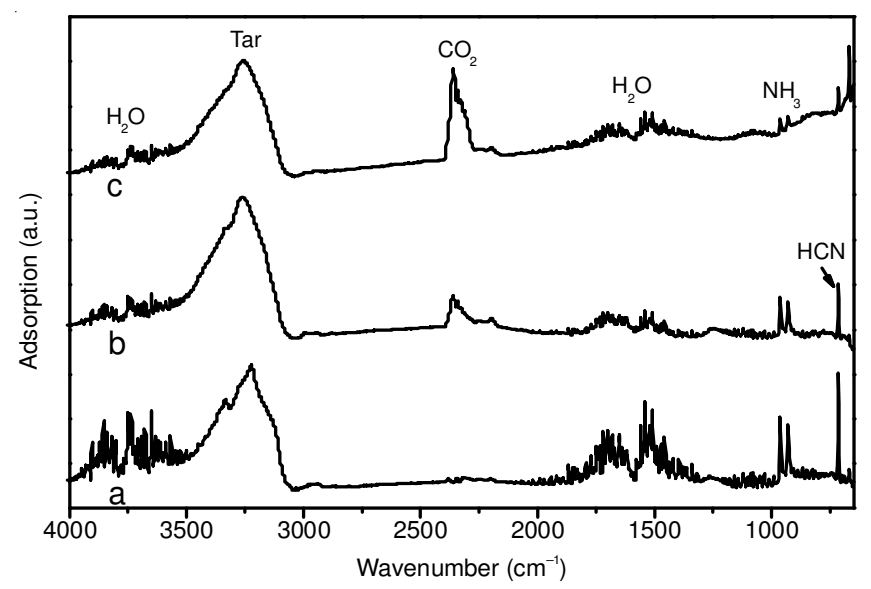

Fig. 6. FTIR spectrum for gaseous products at $352{ }^{\circ} \mathrm{C}$ evolving from fibers stabilized for (a) 0 ; (b) 30; (c) $60 \mathrm{~min}$

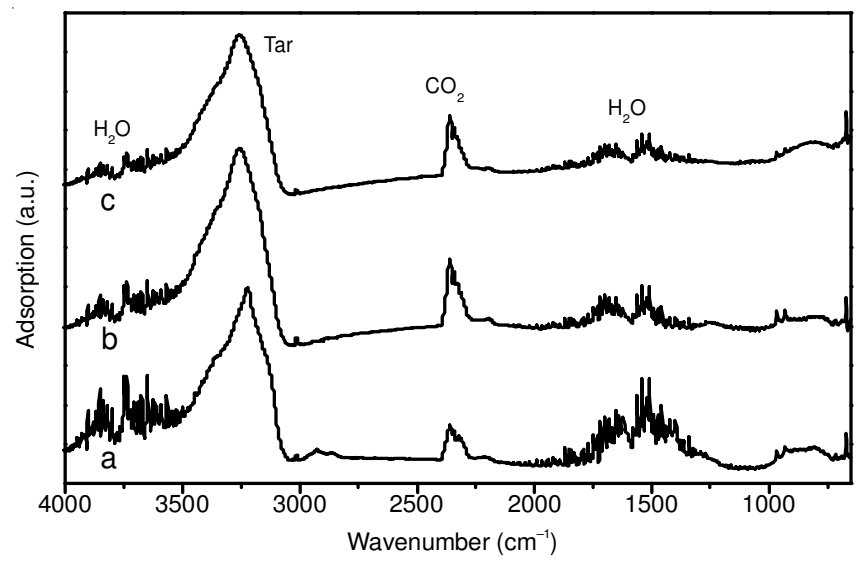

Fig. 7. FTIR spectrum for gaseous products at $602{ }^{\circ} \mathrm{C}$ evolving from fibers stabilized for (a) 0 ; (b) 30; (c) $60 \mathrm{~min}$

residual nitrile groups in stabilized fibers. The band around $962 \mathrm{~cm}^{-1}$ could be observed in Fig. 6(a-c) could be attributed to release of $\mathrm{NH}_{3}$. The strong intensity at the band in Fig. 6(a) indicated that the large amount of $\mathrm{NH}_{3}$ released from precursor fibers. However, few $\mathrm{NH}_{3}$ was detected from stabilized fibers from the weak intensity of the band comparing to the precursors. It is evident that the intensity of $\mathrm{CO}_{2}$ in stabilized fibers Fig. 6(b-c) were stronger than the precursor fiber Fig. 6(a), the main reason was that higher extension of the stabilization of the fiber has high content of oxygen-containing functional groups such as carboxyl, hydroxyl and carbonyl groups ${ }^{32}$.

In the last stage of pyrolysis, the amount volatile gases of all fibers decreased. There were chain secession under such high temperature and more and more non-carbon atoms were expelled during pyrolysis. There were no significant changes in the FTIR spectrum (Fig. 7) shown in at $6500^{\circ} \mathrm{C}, \mathrm{H}_{2} \mathrm{O}, \mathrm{CO}_{2}$, tars and small amount of $\mathrm{NH}_{3}$ were main product. However, the amount of the each gas decreased for the diminished residual nitrile groups and perfect formation of ladder structure.

From integrated intensity of the IR spectrum shown in, the evolution of the tar (hydrocarbon organic) was the most released gas in all three fibers and its amount increased as pyrolysis temperature increasing.

An intense evolution of $\mathrm{NH}_{3}$ occurred and reach the maximum rate at $242,267,300{ }^{\circ} \mathrm{C}$ for fibers stabilized for 0 , $30,60 \mathrm{~min}$, respectively, which is together with fast weight 


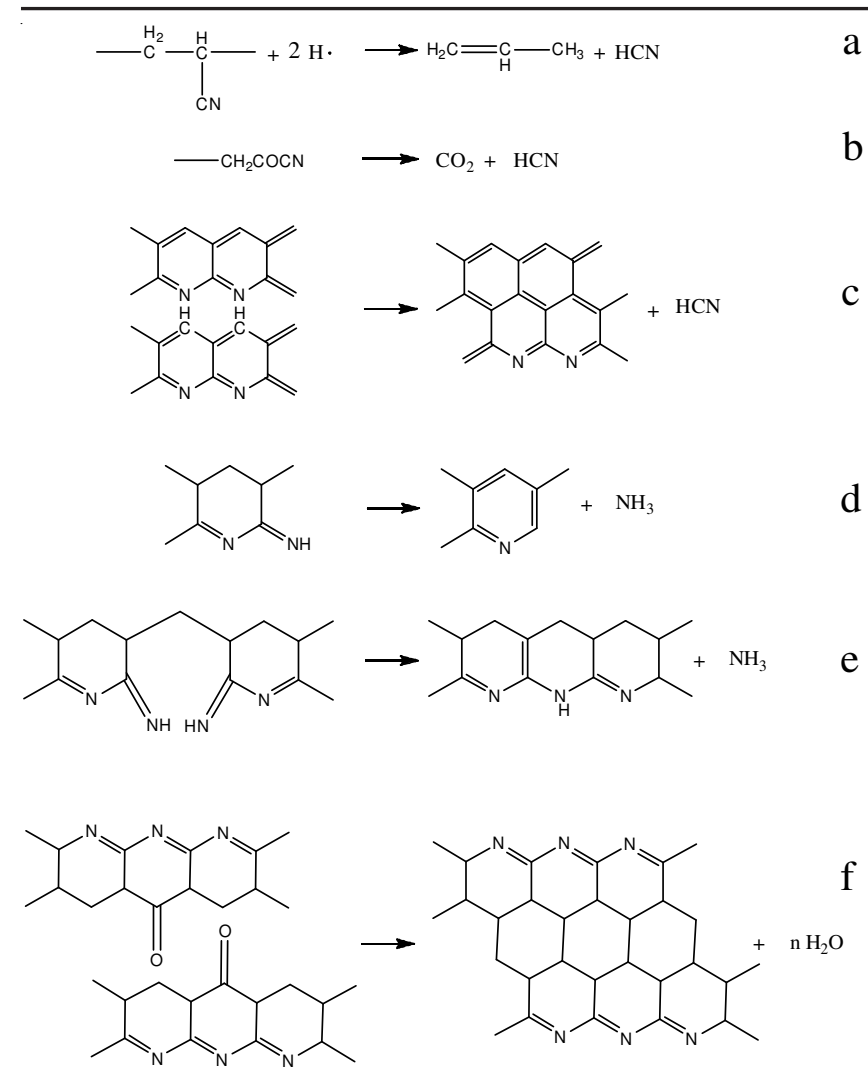

Fig. 8. Formation of the evolution of gaseous products (a), (b), (c) formation of $\mathrm{HCN}$ and $\mathrm{CO}_{2}$; (c), (e) formation of $\mathrm{NH}_{3}$; (f) formation of $\mathrm{H}_{2} \mathrm{O}$
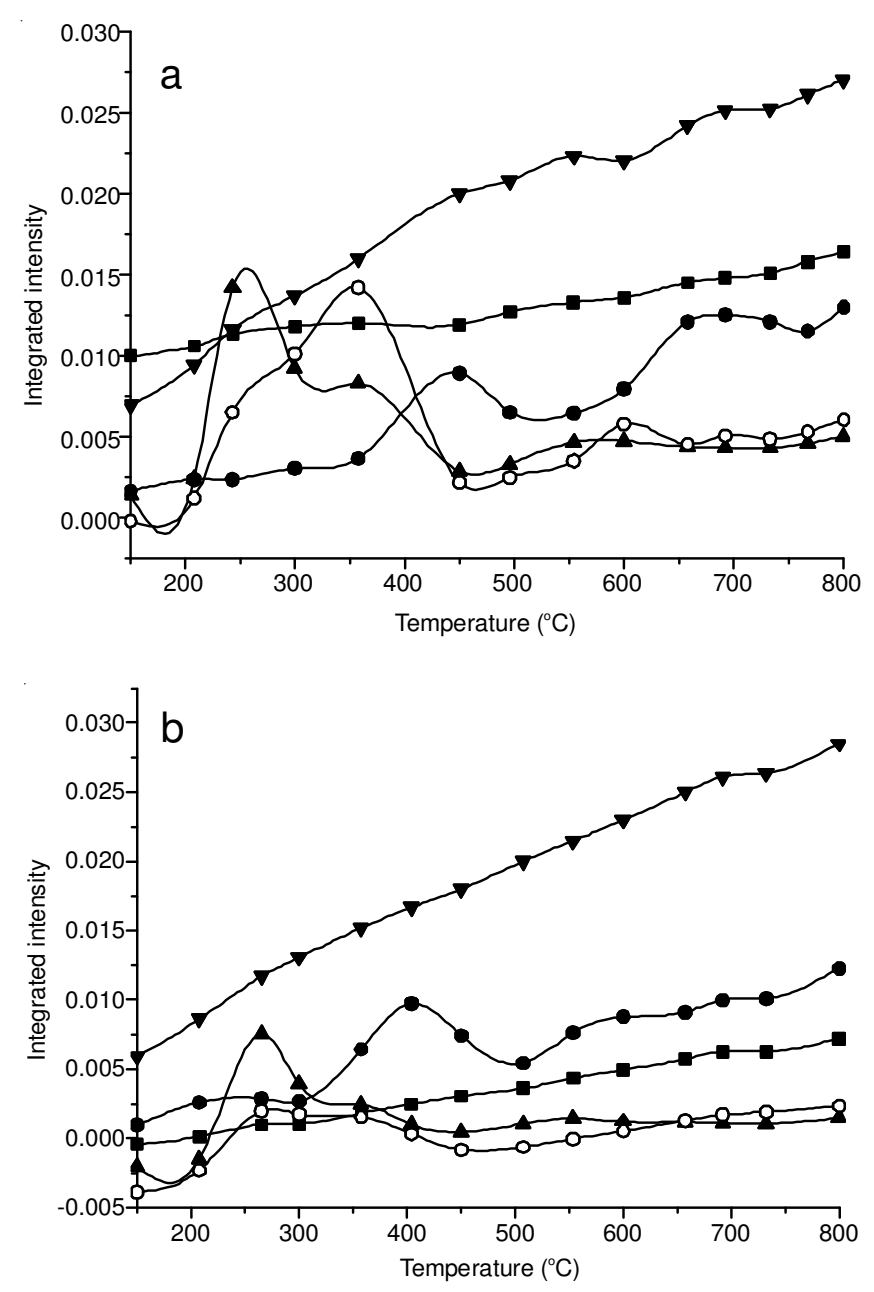

a

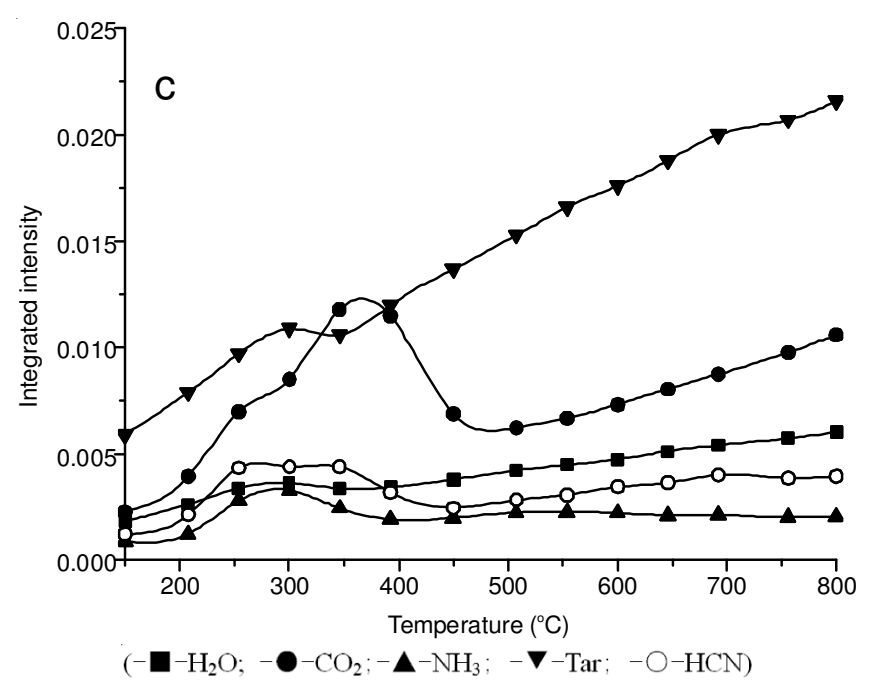

Fig. 9. Evolution with the temperature of pyrolysis of the absorbance of band characteristics of fibers stabilized for (a) 0; (b) 30; (c) $60 \mathrm{~min}$

loss. The release centers of $\mathrm{NH}_{3}$ increased with extent of stabilization and the amount of release $\mathrm{NH}_{3}$ is: $\mathrm{a}>\mathrm{b}>\mathrm{c}$.

The evolution of $\mathrm{CO}_{2}$ from a had two peaks centered at 447 and $694{ }^{\circ} \mathrm{C}$, however, only a single peak of intensity which centered at 402 and $345^{\circ} \mathrm{C}$ could be observed for 'b', 'c' respective. Meanwhile, highly stabilized fiber 'c' released highest $\mathrm{CO}_{2}$ for the oxygen-contained groups.

The evolution of $\mathrm{H}_{2} \mathrm{O}$, stating from $150-800{ }^{\circ} \mathrm{C}$, were steady and dominant for all the fibers during the whole pyrolysis process (Figs. 8 and 9).

As expected, the evolution of $\mathrm{HCN}$ could be detected from infrared spectrum in the fibers starting from $200-800{ }^{\circ} \mathrm{C}$. Compared with 'b' and 'c'. (a) Show the most intense evolution of $\mathrm{HCN}$ with absorption at band round $713 \mathrm{~cm}^{-1}$. The precursor fiber without treatment, the emission of $\mathrm{HCN}$ would be larger, corresponds well to the maximum weight loss rate of precursor. For stabilized fibers in (b-c), the residual un-reacted polyacrylonitrile polymer chains could be cyclized to form ladder structure.

\section{Conclusion}

Extensive experiment using thermogravimetric analysis coupled with Fourier transform infrared analysis (TG-FTIR) is performed to investigate the pyrolysis of fibers with different extent stabilization. The result found that the pyrolysis can be divided into three stages and most of the weight loss occurs at the second stage. In another word, thermal stability of fibers increased with extent of stabilization; $\mathrm{H}_{2} \mathrm{O}, \mathrm{CO}_{2}, \mathrm{HCN}, \mathrm{NH}_{3}$ and tars are main evolved gases in the pyrolysis for dehydrogenation and cracking reaction of polymer chain and amount of each gases is related to extent of stabilization which is the most critical factors influence the reluctant carbon fibers.

\section{REFERENCES}

D.D. Edie, Carbon, 36, 345 (1998).

A. Shindo, Carbon, 2, 391 (1964).

H. Ogawa, Carbon, 38, 211 (2000).

4 A.K. Gupta, D.K. Paliwal and P. Bajaj, J. Macromol. Sci.-Rev. Macromol. Chem. Phys., C31, 48 (1991).

5 J.P. Riggs, Encyclopedia of Polymer Science and Engineering, Wiley, New York (1989). 
6 K. Sudo and K. Shimizu, J. Appl. Polym. Sci., 44, 127 (1992).

7 D. Zhang and Q. Sun, J. Appl. Polym. Sci., 62, 367 (1996).

8 J.A. Newell, D.D. Edie and L.E. Fuller, J. Appl. Polym. Sci., 60, 825 (1996).

9 P. Morgan, Carbon Fibers and Their Composites. Taylor \& Francis, New York (2005)

10 M.S.A. Rahaman, A.F. Ismail and A. Mustafa, Polym. Degrad. Stab., 92, 1421 (2007)

11 S.B. Stanislav, V.A. Igor and V.M. Irina, Thermochim. Acta, 507, 9 (2010).

12 P.J. Snchez-Soto, M.A. Avils, J.C. del Ro, J.M. Gins, J. Pascual and J.L. Prez Rodrguez, J. Anal. Appl. Pyrol., 58-59, 155 (2001).

13 N. Grassie and J.N. Hay, J. Polym. Sci., 58, 189 (1962).

14 K. Miyamiti, M. Okamoto, O. Ishizuka, M. Katayama and S.-I. GakkaiShi, J. Appl. Phys., 22, 538 (1966).

15 A.M. Sarmadi, C.J. Noel and J.B. Birch, Ind. Eng. Chem. Res., 29, 1640 (1990).

16 D.M. Riggs, R.J. Shuford and R.W. Lewis, Hand Book of Composites; Van Nostrand Reinhold, New York, Ch. 11, pp. 196-271 (1982).

17 M.J. Bortner, Ph.D. Dissertation, Virginia Polytechnic Institute and State University (2003).
18 R.C. Houtz, Textile Res. J., 20, 789 (1950).

19 W.J. Burlant and J.L. Parsons, J. Polym. Sci., 22, 249 (1956).

20 E.M. Lacombe, J. Polym. Sci., 24, 152 (1957).

21 N. Grassie, J.N. Hay and C. Mcneilli, J. Polym. Sci., 31, 205 (1958).

22 N. Grassie and J. Hay, J. Polym. Sci., 56, 189 (1962).

23 A.E. Standage and R. Prescott, Nature, 211, 688 (1969).

24 H.N. Friedlander, L.H. Peebles, J. Brandrup and J.R. Kirby, Macromolecules, 1, 79 (1968).

25 W. Watt and W. Johnson, Nature, 257, 210 (1975).

26 K. Morita, Y. Murata, A. Ishitani, K. Murayama, T. Ono and A. Nakajima, Pure Appl. Chem., 58,45 (1986).

27 W.X. Zhang, J. Liu and G. Wu, Carbon, 41, 2805 (2003).

28 P. Bajaj, T.V. Sreekumar and K. Sen, J. Appl. Polym. Sci., 79, 1640 (2001).

29 Q.Y. Qin, C. Lu, H.J. Wang and K.X. Li, Polym. Degrad. Stab., 93, 1415 (2008).

30 X. Tao and X.M. Huang, Fuel, 89, 2185 (2010).

31 P.R. Solomon, T.H. Fletcher and R.J. Pugmire, Fuel, 72, 587 (1993).

32 J.B. Yang and N.S. Cai, J. Fuel Chem. Technol., 34, 650 (2006). 